\title{
South County Government Area in Arroyo Grande - Concept Plan
}

A Project by the Second Year Graduate Class, MCRP, 2003

This quarter long class project was developed in the Project Planning Lab (CRP-553) with instructor Vicente del Rio, during the spring quarter 2003, in collaboration with the City of Arroyo Grande's Community Development Department. The project was the recipient of the 2003 Academic Award from the California Chapter of the American Planners Association - Central Coast Section.

This project is typical of Cal Poly's learn-by-doing philosophy and CRPs community-outreach pedagogy. A group of 17 graduate MCRP students with varied professional backgrounds engaged in developing a design scenario for an area in Arroyo Grande, in response to the needs of City, County, and community needs. The proposed program, the design concept, and the guidelines contributes to a stronger collaboration of the parties involved, and a consensual solution for the area.

\section{THE PROJECT SITE}

Located on West Branch Avenue in Arroyo Grande, the project area encompasses approximately 40 acres and it is made up of six adjacent parcels owned by the County of San Luis Obispo and the City of Arroyo Grande. The larger portion is owned by the county that plans to dedicate it to a future "south county government center" for which it still does not have a specific program.

It is adjacent to St. Patrick's private school on the north, to the Women's Center on the south, and to single-family residences on the east. Due to its location, proximity to Highway 101, and easy accessibility, this is a strategic area not only for the

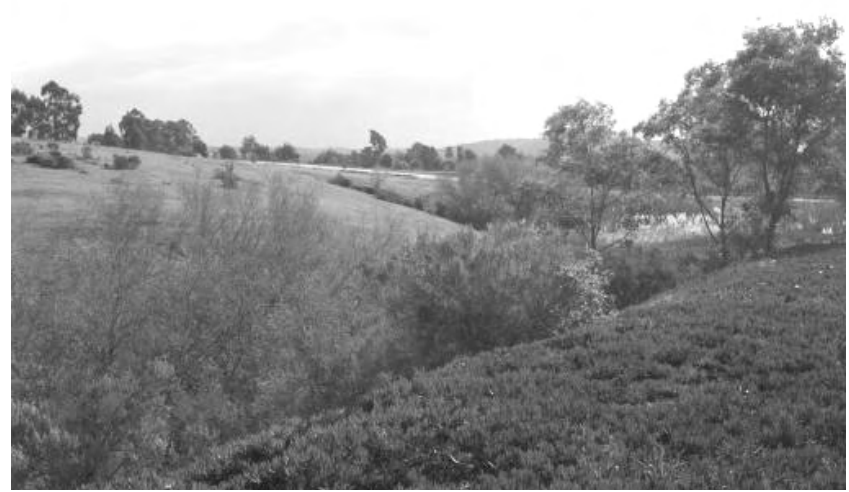

View west from top of the project area county and the city, but also for the community. Most of the area is currently undeveloped but for less than $40 \%$ of the county's property that include the South County Library and offices for the Chamber of Commerce, a Sheriff's substation, and a public works shed and yard. A riparian corridor with a seasonal creek bisects the area, and the topography is mostly gentle but at close proximity to the riparian corridor where slopes go up to $30 \%$; significant sections of the area have already been graded.

\section{THE CONCEPT}

The project's theoretical framework is inspired in classics such as Lynch's and Alexander's, and in concepts from New Urbanism and Smart Growth. The project concept capitalizes on the area's location and the proximity to the Village, as on existing social, economic, and transportation patterns. While it recognizes the split ownership of the site the plan represents a cohesive solution that is feasible for each entity.

The existing needs of the County are fulfilled with new government office space, a library expansion, a "park-n-ride" facility, and the continuation of the corporation yard. City

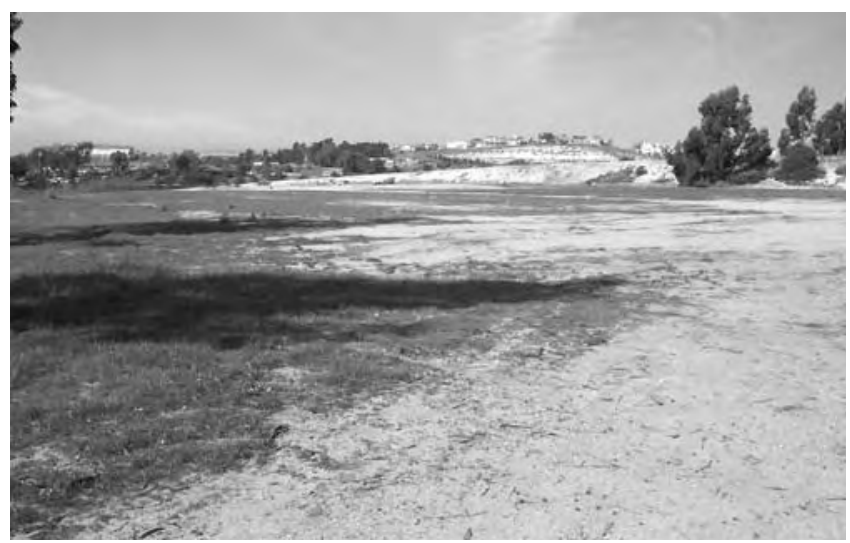

View east to the project area and single-family development beyond. 
needs are responded to by new below market and market rate housing, a new daycare facility, and the expansion of the existing Women's Center.

Community needs are responded to by new cultural facilities and public plazas, the rehabilitation and enhancement of the riparian corridor, passive and active recreation opportunities, and limited convenience commercial space. The plan provides for alternative modes of transportation, and follows a sustainable approach in its total integration to the natural landscape and to the surroundings.

The design parti focuses on the riparian corridor as the major resource and organizing element as it allows for permeability between the different sectors while providing for a strong sense of identity and for a connection to the larger landscape. The distribution of land uses and the design enhance the site being both internally compatible and easily incorporated to existing surrounding uses.

On the County parcel two public plazas - the Government and the Cultural Plazas - are strongly articulated to the riparian corridor and to the recreational area which connects to the City parcel and to the new housing. A network of open space and trails connects all uses both internally and with the surrounding areas. Two small convenience commercial plazas at respond to the new users while providing for lively gateways to the area.

\section{RESULTS}

The project was very well received by all parties involved, and it was successful in considering the area as a development opportunity for an integrative response to the needs of the county, the city, and the community. It allowed students an opportunity to practice project planning in the "real world" - thus serving well Cal Poly's mission of learn-by-doing and community outreach - and it opened an important dialogue between the two planning spheres. By opening possibilities and by showing a plausible development scenario it contributed to a mutually beneficial relationship and served as a catalyst for the discussion of design ideas for a better public realm.

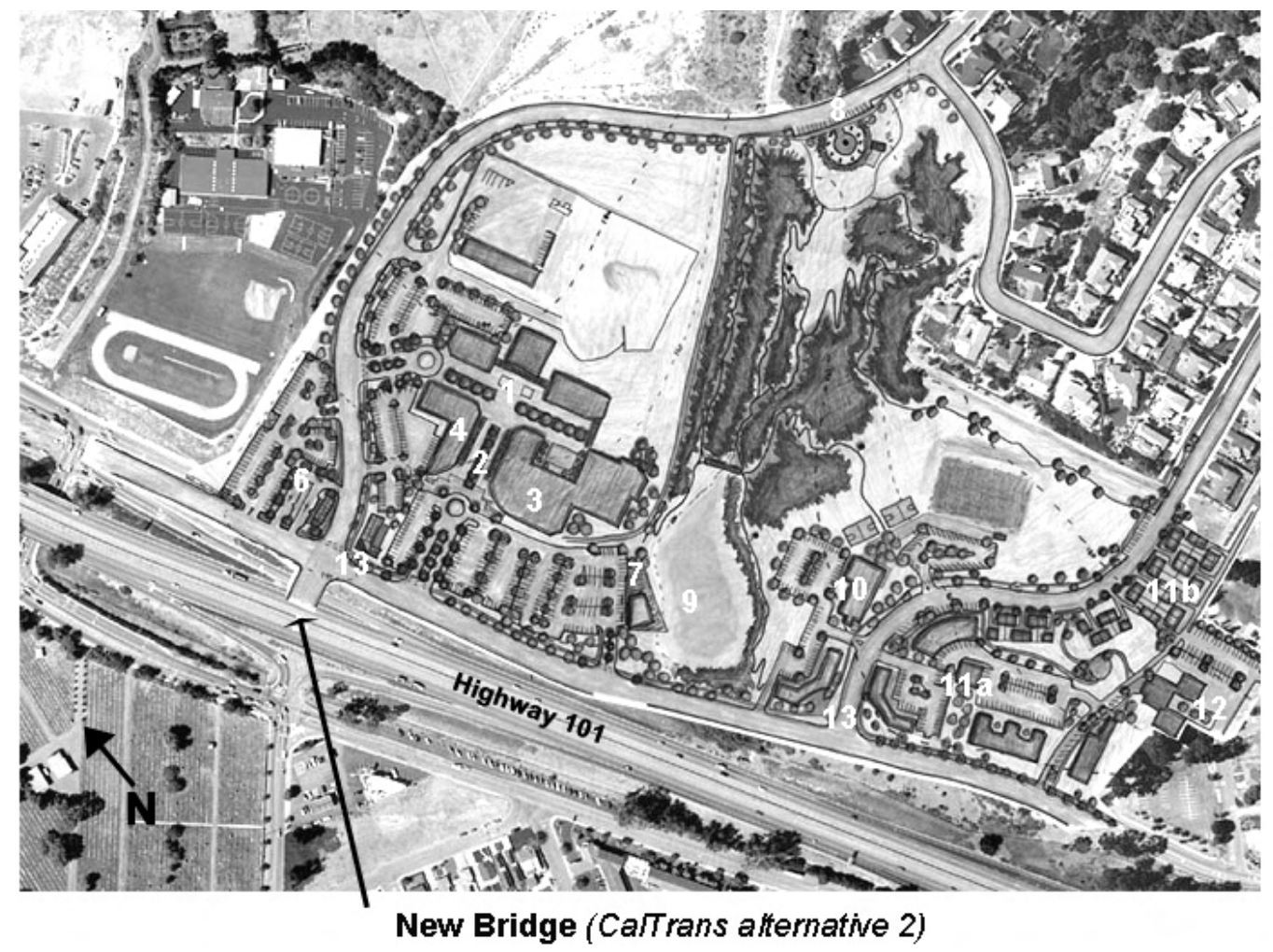

1. Government

Plaza

2 Cultural Plaza

3. Expanded Library

4. Cultural/

Conference

5. Existing Yard

6. Park'n ride

7. Nature Museum /

Restaurant

8. Vista point

9. Retention Pond

10. YMCA

11. Housing

11a. Below Market

11b. Market

12. Day care and Women's Center

13. Commercial 